\title{
IMPROVING NURSING WORK SERVICES THROUGH DEVELOPMENT MODEL OF QUALITY OF NURSING WORK LIFE
}

\author{
Tri Ismu Pujiyanto*, Suprihati Suprihati**, Nursalam Nursalam***, Anastasia Ediyati** \\ *STIKES Karya Husada Semarang, Indonesia \\ **Diponegoro University, Indonesia \\ *** Faculty of Nursing, Universitas Airlangga, Indonesia \\ Email: triismu@yahoo.co.id
}

\begin{abstract}
Introduction: The performance of nurses in a hospital is influenced by the mental and emotional state of the nurse; the higher the workload, the greater the work stress of the nurse. It is a necessity to conduct research to explain a quality of nursing work life model based on the context of Indonesian nurses. Methods: The research process consisted of two stages: observational analytic and model trial. The first phase used cross-sectional design with cluster random sampling technique and obtained 102 samples. The second stage used a quasi-experiment design with pre-post test with control group design and obtained 33 samples. The data was analysed by Partial Least Squares and paired t-test analysis. Results: It was found that the number of the nurses with Burnout Syndrome in the hospital was 67.6\%. The depersonalisation indicator in the low category was $73.5 \%$, and the high category of self-achievement indicators had $89.2 \%$. Conclusions: It can be concluded that improving the performance of care services is more effective through improving the quality of nursing work life. This study found that the nurses' quality of life affected the increased nursing work service because their working scope involves interacting with other professions and the environment.
\end{abstract}

Keywords: quality of nursing work life model, burnout syndrome, self-achievement

\section{INTRODUCTION}

The performance of nurses in a hospital is influenced by the mental and emotional state of the nurse; the higher the workload, the greater the work stress of the nurse. Burnout Syndrome is a manifestation of high stress in working; this term refers to the syndrome of prolonged stress that occurs in the workplace where the result is a combination of workers and their work (Papalia, Olds and Feldman, 2007). Based on the research of Cañadas-De la Fuente et al. (2015), the prevalence of Burnout Syndrome in from a mental fatigue aspect was $25 \%$ on the emotional fatigue dimension, $30 \%$ in the dimension of depersonalisation and $45 \%$ in the self-achievement dimension. Indonesia Ministry of Health conducted a survey which found that $10 \%$ of patients felt dissatisfied with health services in hospitals (Dinas Kesehatan Propinsi Jawa Tengah, 2012). According to Ministerial Decree no. 129 year 2008 on hospital minimum service standards, inpatient satisfaction standard was $\geq 90 \%$, or patient dissatisfaction standard was $\leq 10 \%$ (Abdurrouf, Nursalam and Purwaningsih, 2013). Another research from Suharti and Daulima (2013) presented their research result in Metropolitan Jakarta hospital, in which most of the nurses had moderate $(86.7 \%)$ and high (3.6\%) burnout syndrome.

Based on the preliminary study held at one of regional public hospitals of Semarang it was found that, from 20 nurses, there were eight experiencing burnout syndrome. This shows that the incidence rate of burnout syndrome in this hospital was about $40 \%$ out of 20 sample nurses. The prevalence of burnout syndrome was almost the same in most hospitals (de Paiva et al., 2016); this is due to the high demand of hospitals to nurses to work according to the best standards, which requires great physical and psychological activity from nurses in giving nursing care.

The nursing profession as an integral part of the healthcare system is a critical factor in the success of health services in general and the key to the success of hospital services in particular. Nursing services still need many innovations, such as medical services to increase patient satisfaction as a consumer (Nursalam, 2014). Morsy and Sabra (2015)said that $66.7 \%$ of nurses had experienced job dissatisfaction, which was influenced by organisational culture factors, nurse job characteristics, nursing work quality and burnout syndrome. Burnout syndrome is a dominant factor in decreasing service performance in hospitals (Gilbert Khosa et al., 2014; Khamisa et al., 2015; Thulth and Sayej, 2015).

The low quality of nursing service can be caused by many factors, such as quality of nursing work life and burnout syndrome (Manwatkar and Mathew, 2016). A study of (Suresh, 2013) conducted in several hospitals in India found that $48 \%$ of nurses had a bad 
QNWL (Quality Nursing Work Life). Khamisa et al. (2015) in Africa, found nurses with emotional exhaustion contributed to $14 \%$ of treatment while emotional exhaustion and depersonalisation contributed $31 \%$ in reducing the performance of nursing service in the hospital.

According to previous research by Momeni et al. (2016) regarding quality of nursing work life in Mazandaran, Iran scored $27,2 \%$ of quality of nursing work life as low, $61.7 \%$ was categorised as average, and $6.7 \%$ had good quality of nursing work life. This situation shows that most of the quality of nursing work life is low, which can be an indicator of stress for nurses that work in the hospital.

Mark and Smith (2012) stated that many factors cause stress in nurses, such as a conflict with a doctor, discrimination, over workload, handling many patients, patients' death and problem with patients' families. Beh (2016) held a research about stress impact on nurses which showed that $52 \%$ resulted in headache, $43 \%$ caused anger, $38 \%$ caused fatigue, $38 \%$ caused low interpersonal interaction and $24 \%$ caused low concentration. On the other hand, Nishitani, Sakakibara and Akiyama (2013) concluded that lack of sleep was one of the causes of depression for employees and anxiety syndrome for employees.

Efforts to reduce stress in nurses can be made through reforming the quality of nursing work life. A study by Borhani et al. (2016) in Teheran, Iran, concluded that the reforming of quality of nursing work life can improve the nursing service that is given to patients and the quality of nursing work life can increase nurses' role towards organisation of the nursing profession. The previous research shows the quality of nursing work life has positive impact and significance toward nursing work (Manwatkar and Mathew, 2016). Meanwhile, Borhani et al., (2016) concluded that the improvement of medical service in hospitals can be started from moral improvement and learning through the environment around the hospital.

Based on the description of the background above, it is necessary to develop a quality of nursing work life in accordance with the condition of nurses in Indonesia. The development of this model will be a solution in reducing the level of nurse stressors in
Indonesia in providing therapeutic care in hospitals.

\section{MATERIALS AND METHODS}

The research process consisted of two stages, the first was observational analytic research and the second was a quality of nursing work life model. The first phase used cross-sectional design with cluster random sampling technique. The sample population were 102 samples. The variables in this research were analysed by using Structural Equation Modelling (SEM), in such a way that the minimum samples needed were $100-150$ subjects. The number of samples for the first research had six variables, so this research needed 17 indicators with six variables, which was equal to 102 samples.

There were two variables in this research, exogenous and endogenous. The exogenous variable consists of organisational culture, nurse factors, job characteristics, and quality of nursing work life. Meanwhile, endogenous consists of burnout syndrome and nursing service. The data analysis used univariate analysis and then analysed using PLS (partial least square). PLS is an indeterminacy factor of powerful analytical methods used to confirm the theory (Ghozali, 2014).

The second stage used a quasiexperiment design with pre-posttest with control group design. The method used in the intervention was a structural model which emphasised the process of socialisation, externalisation, combination and internalisation. The provision of interventions used modules. The number of samples was calculated based on Sastroasmoro and Ismael (2011) formula and obtained 33 samples then performed simple random sampling. Data analysis used univariate analysis and bivariate analysis (paired t-test).

Data collection used questionnaires that contained questions according to the research variables. The study was conducted at the Dr. Adhyatama, MPH Regional Public Hospital of Semarang in the surgical wards and paediatric wards around July - September 2017. This research passed the ethical clearance conducted at Faculty of Medicine Diponegoro University and was registered with number 454/EC/FK-RSDK/VII/2017. The researcher asked consent from 
Improving Nursing Work Services Through ... (Tri Ismu Pujiyanto et.al.)

respondents upon their agreement to participate on this study.

\section{RESULTS}

Table 1 shows that the mean age of nurses is 32.76 years, which belong to the productive age. Based on the educational status it was found that the largest percentage is nurses with a bachelor degree, or $54.9 \%$ while the lowest educational background is a master degree $(1 \%)$. This situation indicates that most qualifications are bachelor degree, which is appropriately matched with the standard. Marital status of respondents was mostly married (79.4\%)

Table 2 shows the lowest organisational culture is the success criteria with the low category of $15.7 \%$ and the mean is 2.28. Success criteria are an indicator of self-achievement for nurses. In addition to the success criteria, the organisational factors that are still low are the orientation of the organization, with $31.4 \%$ and an average of 2.42. This is followed by strategy emphasis indicator, which is equal with $33.3 \%$, and $31.4 \%$ organisational orientation. Organisational culture of nurses' indicator of closeness of good category organisation showed a percentage of $75.5 \%$ with mean 2.63 .

Table 3 shows that the characteristics of nurses on the medium criterion indicator is $49.0 \%$ with mean 3.67 , while the mental indicator model in the good category has a percentage equal to $91.2 \%$ with mean 4.26. The mental model is an assumption held by every individual and organisation that can determine how to act.

Table 4 shows the indicator of job variation with the low criterion of $27.5 \%$ with the mean of 0.61 , while the job feedback indicator on the good criterion is $42.2 \%$. Task

Table 1. Demographic characteristic of the respondents

\begin{tabular}{lcc}
\hline Characteristic of the nurse & $\mathbf{n}$ & \% \\
\hline Age & 102 & $32.76 \pm 5.9$ (Mean \& SD) \\
\hline Education & 45 & 44.1 \\
Vocational degree & 56 & 54.9 \\
Bachelor degree & 1 & 1,0 \\
Master degree & 0 & 0 \\
Doctoral degree & & \\
\hline Marital status & 18 & 17.6 \\
Single & 81 & 79.4 \\
Married & 3 & 2.9 \\
Widower & & \\
\hline
\end{tabular}

Table 2. Distribution of organisational culture

\begin{tabular}{lcccccc}
\hline \multirow{2}{*}{ Organisational culture } & \multicolumn{3}{c}{ Criteria } & \multirow{2}{*}{ Total (\%) } & \multirow{2}{*}{ Mean } & \multirow{2}{*}{ Score } \\
\cline { 2 - 4 } & Good (\%) & Moderate (\%) & Bad (\%) & & \\
\hline Organisational orientation & $66(64.7)$ & $32(31.4)$ & $4(3.9)$ & $102(100)$ & 2.42 & $1-3$ \\
\hline Organisational leadership & $71(69.6)$ & $18(17.6)$ & $13(12.7)$ & $102(100)$ & 2.49 & $1-3$ \\
\hline Management of staff & $55(53.9)$ & $35(34.3)$ & $12(11.8)$ & $102(100)$ & 2.46 & $1-3$ \\
\hline Organizational closeness & $77(75.5)$ & $22(21.6)$ & $3(2.9)$ & $102(100)$ & 2.63 & $1-3$ \\
\hline Strategy emphasis & $62(60.8)$ & $34(33.3)$ & $6(5.9)$ & $102(100)$ & 2.43 & $1-3$ \\
\hline Success criteria & $51(50.0)$ & $35(34.3)$ & $16(15.7)$ & $102(100)$ & 2.28 & $1-3$ \\
\hline
\end{tabular}

Table 3. Distribution characteristics of nurses.

\begin{tabular}{lcccccc}
\hline \multirow{2}{*}{$\begin{array}{c}\text { Characteristics of } \\
\text { the nurse }\end{array}$} & \multicolumn{3}{c}{ Criteria } & \multirow{2}{*}{ Total (\%) } & Mean & Score \\
\cline { 2 - 4 } & Good (\%) & Moderate (\%) & Bad (\%) & & & $102(100)$ \\
\hline Commitment & $82(80.4)$ & $20(19.6)$ & $0(0.0)$ & 3.88 & $1-5$ \\
\hline Mental Model & $93(91.2)$ & $6(5.9)$ & $3(2.9)$ & $102(100)$ & 4.26 & $1-5$ \\
\hline Motivation & $81(79.4)$ & $21(20.6)$ & $0(0.0)$ & $102(100)$ & 3.94 & $1-5$ \\
\hline Attitude & $52(51.0)$ & $50(49.0)$ & $0(0.0)$ & $102(100)$ & 3.67 & $1-5$ \\
\hline
\end{tabular}

Table 4. Distribution of job characteristics of nurses.

\begin{tabular}{lcccccc}
\hline \multirow{2}{*}{ Job characteristics } & \multicolumn{3}{c}{ Criteria } & \multirow{2}{*}{ Total (\%) } & \multirow{2}{*}{ Mean } & \multirow{2}{*}{ Score } \\
\cline { 2 - 4 } & Good (\%) & Moderate (\%) & Bad (\%) & & & \\
\hline Work feedback & $43(42.2)$ & $46(45.1)$ & $13(12.7)$ & $102(100)$ & 0.76 & $0-1$ \\
\hline Task Variety & $11(10.8)$ & $63(61.8)$ & $28(27.5)$ & $102(100)$ & 0.61 & $0-1$ \\
\hline
\end{tabular}


Table 5. Distribution of burnout syndrome

\begin{tabular}{lcccccc}
\hline \multirow{2}{*}{ Nursing Work Service } & \multicolumn{3}{c}{ Criteria } & \multirow{2}{*}{ Total (\%) } & Mean & \multirow{2}{*}{ Score } \\
\cline { 2 - 4 } & High (\%) & Medium (\%) & Low (\%) & & & \\
\hline Emotional Fatigue & $2(2.0)$ & $31(30.4)$ & $69(67.6)$ & $102(100)$ & 1.64 & $0-6$ \\
\hline Depersonalisation & $3(2.9)$ & $24(23.5)$ & $75(73.5)$ & $102(100)$ & 1.24 & $0-6$ \\
\hline Self-achievement & $91(89.2)$ & $9(8.8)$ & $2(2.0)$ & $102(100)$ & 5.19 & $0-6$ \\
\hline
\end{tabular}

Table 6. Distribution of service performance

\begin{tabular}{lcccccc}
\hline \multirow{2}{*}{ Service Performance } & $\begin{array}{c}\text { Good } \\
(\%)\end{array}$ & Moderate (\%) & Low (\%) & Total (\%) & Mean & Score \\
\cline { 2 - 3 } & $101(99.0)$ & $1(1.0)$ & $0(0.0)$ & $102(100)$ & 4.54 & $1-5$ \\
\hline Nursing Care Standard & $102(100)$ & $0(0.0)$ & $0(0.0)$ & $102(100)$ & 4.52 & $1-5$ \\
\hline $\begin{array}{l}\text { Professional Performance } \\
\text { Standard }\end{array}$ & $31(30.4)$ & $69(67.6)$ & $2(2.0)$ & $102(100)$ & 3.43 & $1-5$ \\
\hline Nursing Satisfaction & & & &
\end{tabular}

Table 7. Results of the model development of the working quality model of nurses' work (QNWL) on increased nursing work service at the hospital

\begin{tabular}{lcl}
\hline \multicolumn{1}{c}{ Relationship between variables } & Coefficient & Information \\
\hline Organisational culture with QNWL & 0.55 & Significant \\
Characteristics of the nurse with QNWL & 0.33 & Significant \\
QNWL with nurse performance & -1.07 & Significant \\
\hline
\end{tabular}

variations include discussion with peers, seminars, workshops or continuing education.

Table 5 shows that the burnout syndrome among nurses with the indicator of low emotional fatigue category is $67.6 \%$ with the mean of 1.64. Emotional fatigue is characterized by physical, mental or emotional fatigue that lasts for a long time. The depersonalisation indicator in the low category was $73.5 \%$ with an average of 1.24 , characterised by less sensitivity or less care towards the patient and a tendency to withdraw from the work environment. The highest category of self-achievement indicators has a value of $89.2 \%$, which includes feelings of helplessness, disrespect and feeling the tasks imposed on the official are too great.

Table 6 shows that service performance applied to the nursing care standard indicator is $99.0 \%$ with 4.54 average, as well as $100 \%$ professional performance standard with a mean of 4.52 .

Based on the model analysis results obtained it shows that the organisational culture affects QNWL. Characteristics of nurses significantly affect QNWL and QNWL significantly affects service performance. Based on the model results, it can be concluded that improving the performance of care services can be done more effectively through QNWL.

\section{DISCUSSION}

\section{The relationship of organisational culture to the performance of nurses}

In this study, the researcher found that there is a significant correlation between organisational culture and nurse performance. This situation can be caused by organisational culture that can cause changes in work rhythm, especially for nurses. The existence of a new policy can affect the work patterns of the hospital, such as leadership and system changes. In this study, the hospital that was chosen was a government hospital, so that service performance that is often perceived by society is lower than when compared with private hospitals. One fundamental difference is that the existing systems in government hospitals are different from those in private hospitals as well as there being different financing systems between government hospitals and private hospitals. This situation causes the service performance between public hospitals and private hospitals to be different. The results of this study are in line with previous research conducted by (Sharma and Kamra, 2013)

The results of this study are in line with the opinion from Qaisar, Rehman and Suffyan (2012) which states that organisational commitment among employees is an important aspect, as a result of which they perform better. Low commitment can 
lead to poor service performance (Hamdi and Rajablu, 2012). Nurses are human resources who participate in colouring health services in hospitals. Therefore, nursing service has a contribution to this.

\section{Relationship between characteristics of nurses and the quality of life of nurses' work}

There is a significant correlation between nurses' characteristics with the quality of work life of nurses. This situation can be caused by the emotional and spiritual circumstances of the nurse that affect the pattern of nurse perception in performing hospital care services. Nursing work perceived as a burden is a source of stressor for the nurse, so that it impacts the pattern of life of nurses in the family and society. Changes in life patterns can be seen from the attitude and behaviour of nurses in everyday life at home.

Nursing behaviour patterns in running care services can easily make nurses being emotional. Changes in the work design are important for nurses to improve the quality of care that is provided for patients. According to previous research by Nursalam (2012), design of the nursing work can be done principally in the efficiency of the work, so that the nursing service process does not cause a stressor. The efficiency of job design can be done with work shift management for nurses, work-off systems and reward systems.

Motivation of nurses in running the service can be a factor that affects the state of nurses' life. Motivation is an important factor for nurses in providing patient care services. Previous research by Faraji Khiavi et al. (2015) states that the low motivation of nurses can cause low performance in the hospital.

\section{Relationship of nurse characteristics with nurse performance}

Based on the results of the analysis, it is found that the characteristic of nurses that most significantly affects the quality of working life is home dimension. Based on the results of the analysis it is found that the most significant nurse characteristics affecting burnout syndrome is self-actualisation

According to the results of the study, it is found that there is a relationship between job characteristics and the quality of life of nurses in hospitals. This situation can be caused by a variety of complex tasks imposed on the nurse and it is shown by the percentage of moderate to low category variation categories. The state of task variation can cause the nurses to experience fatigue in working, so that some aspects of the life needs of nurses is cyclically changed, such as time with family because, when they are in family time, they are still doing the task. This circumstance leads to changes in the quality of life of nurses.

Konstantinos and Christina (2008) concluded that the characteristic factors of nurses related to job satisfaction include the characteristics of the organisation, relationship with staff and patient care related to work stress. Collaboration between nurses and physicians is significantly related to work stress and a significant relation to job satisfaction. Collaboration between nurses' colleagues relates significantly to leadership and job satisfaction. Thus, leadership is related to nurse job satisfaction.

Konstantinos and Christina (2008) emphasise that the interaction aspects between individual circumstances (nurses), the environment of the nurse and the circumstances influence nurses' work. Individual circumstances include the characteristic state of the nurse, such as age, length of work, education, marital status and income. Conditions associated with the organisation include leadership, nurse workload and issues related to the nursing organisation. Environmental circumstances of the nurse include interaction between patient and nurse, interaction between nurse and doctor and nurse authority in providing care services.

Characteristics of nurses in burnout syndrome based on the results of research found that there is a significant relationship between job characteristics with burnout syndrome. This situation can be caused by a variety of tasks and the impact of the job as the source of stressor for nurses, which can be seen from the work of nurses which requires performing a comprehensive job regarding the patient. Job feedback has an impact on the emotional and spiritual state of the nurse, which can be reflected in the results of this study, indicating the low attitudes and commitment of nurses in running care services.

The nurse profession is central to the service centre given to the patient, so that the patient is concerned with the services provided 
by the nurse to the patient. Nursalam (2014) mentions that the main role of nurse professionals is to provide nursing care to the patient (as the main object of study of nursing philosophy, which includes: 1) Paying attention to the individual in the context of the life and needs of the client; 2) Nurses use the nursing process to identify nursing problems, including physical, psychological, social and spiritual examinations; 3) Providing nursing care to clients (clients, families and communities) ranging from simple to complex.

The complex role of a nursing and the holistic demands of service lead to an emotional change in the nurse. This situation is supported by the results of research that show the low attitudes of nurses to the service, so that the nurse is experiencing a distressed perception in running the service in the hospital. Perception of pressure when working is the cause of burnout syndrome in nurses.

\section{Characteristics of work with the performance of nurses}

The results show that job characteristics significantly affect the performance of nurses. This situation can be caused by a heavy burden of duty for the nurse and high task variations, which lead to burnout conditions, thereby degrading the quality of nursing work. The quality of nursing work is decreased due to fatigue experienced by nurses.

The results of this study are in line with research by Khamisa, Peltzer and Oldenburg (2013) which states that the impact of burnout syndrome can affect the health of the nurses themselves. The circumstances of burnout can be caused by the long-lasting state of stress experienced by nurse, so that burnout syndrome occurs. Khamisa, Peltzer and Oldenburg (2013) mention that the cause of burnout syndrome in heavy workload has an impact of health itself.

Work-related stress can affect job satisfaction. The stressful state of work that lasts long will disrupt the health of nurses. Factors associated with the health condition of nurses include the stress experienced by nurses, which affects the nursing work condition in the provision of services to the patient. The nurse's stress condition leads to a decrease in job satisfaction, which affects the health condition of the nurse in general.

\section{The relationship between nurse's quality of life and the performance of the nurse}

Based on the results of the study it is found that nurses' quality of life significantly affects the performance of services. Circumstances can be caused by a nurse's work system, which always interacts with other professions and patients who change each day, causing the need for emotional skill in adapting to new circumstances. This situation causes pressure in the work so that it has an effect on the output of services provided by the nurse.

The nursing profession is a fundamental profession in patient care in hospitals, so the quality of service in the hospital rests on providing services provided by nurses to patients. Several previous researches conducted by Borhani et al. (2016) in Tehran, Iran, concluded that improving the nurses' quality of work life can improve the service performance provided by nurses to patients in the hospital. A study of Sirin and Sokmen (2015) in Turkey mentioned there are five indicators used in measuring the quality of work life of a nurse; they are work environment, relationship with manager, job condition, job perception and service support.

Horrigan et al. (2013) state that quality of work life reveals the importance of respect for humans in their work environment. Thus, the important role of quality of work life is to change the organisational climate in order to technically and humanely bring about a better quality of work life. Quality of work life formulates every policy process decided by a company in response to what their employees desire and expect.

The environmental factors of nurse work are important factors that influence the nurse's service to the patient. Kivimäki et al. (2008) state that the nurses' work environment factors include the physical environment in the workplace, home and various work rules that shape the atmosphere and working spirit of nurses that are implicated in performance. Meanwhile, Horrigan et al., (2013) stated that positive nursing work quality can support high-quality patient care and contribute to the continuation of the healthcare system.

\section{CONCLUSIONS}

The quality of nursing work life model in accordance with the condition of Indonesian 
nurses is influenced by organisational culture, nurse characteristics, job characteristics and efficient nursing life quality. It can be concluded that improving the performance of care services is more effective through the quality of nursing work life and in reducing the state of increased nursing work service among nurses is more effective through QNWL. The study found that the nurses' quality of life affects the incidence of increasing nursing work service, because their working scope involves interacting with other professions and the environment. The benefit of intervention in quality of nursing work life is to improve understanding in working, so that it can encourage the learning process. The typical Indonesian nurse QNWL model needs to be tested on other nurse work environments, so it can correct the possibility of imperfections in this research data. In addition, testing is required in the application of interventions to prevent burnout syndrome in nurses based on this model.

\section{REFERENCES}

Abdurrouf, M., Nursalam and Purwaningsih (2013) 'Islamic Caring Model on Increase Patient Satisfaction', Jurnal Ners, 8(1), pp. 153-164. doi: http://dx.doi.org/10.20473/jn.v8i1.3893.

Beh, L.-S. (2016) 'Job Stress and Coping Mechanisms among Nursing Staff in Public Health Services Leap-Han Loo', International Journal of Academic Research in Business and Social Sciences, 6(5), pp. 131-176. doi: 10.6007/IJARBSS/v6-i5/2164.

Borhani, F. et al. (2016) 'Assessment of Predictable Productivity of Nurses Working in Kerman University of Medical Sciences' Teaching Hospitals via the Dimensions of Quality of Work Life', Global Journal of Health Science, $8(10), \quad$ p. $65 . \quad$ doi: 10.5539/gjhs.v8n10p65.

Cañadas-De la Fuente, G. A. et al. (2015) 'Risk factors and prevalence of burnout syndrome in the nursing profession', International Journal of Nursing Studies, 52(1), pp. 240-249. doi: 10.1016/j.jinurstu.2014.07.001.

Dinas Kesehatan Propinsi Jawa Tengah (2012) 'Buku Profil Kesehatan Provinsi Jawa Tengah Tahun 2012', Buku Profil
Kesehatan Provinsi Jawa Tengah Tahun 2012, 3511351(24), pp. 1-118.

Faraji Khiavi, F. et al. (2015) 'Effect of final evaluation on job motivation from the perspective of nurses in Ahvaz Hospitals in 2012.', Journal of medicine and life. Carol Davila - University Press, 8(Spec Iss 4), pp. 209-213. Available at: http://www.ncbi.nlm.nih.gov/pubmed/2 8316733 (Accessed: 18 November 2017).

Ghozali, I. (2014) Partial least squares konsep, Metode dan Aplikasi Menggunakan Porgram Warp PLS 4.0. Semarang: Badan Penerbit Universitas Diponegoro.

Gilbert Khosa, M. et al. (2014) 'Impact of Occupational Stress and Burnout on Employee Job Performance: A Study of Nurses in Rural Clinics of Bushbuckridge in Mpumalanga Province', International journal of Innovative Research in Management ISSN, 1(1), pp. 2319-6912.

Hamdi, S. and Rajablu, M. (2012) 'Effect of Supervisor-Subordinate Communication and Leadership Style on Organizational Commitment of Nurses in Health Care Setting', International Journal of Business and Management, 7(23), pp. 7-18. doi: 10.5539/ijbm.v7n23p7.

Horrigan, J. M. et al. (2013) 'Evaluating and Improving Nurses' Health and Quality of Work Life', Workplace Health \& Safety. SAGE PublicationsSage CA: Los Angeles, CA, 61(4), pp. 173-181. doi: $10.1177 / 216507991306100405$.

Khamisa, N. et al. (2015) 'Work related stress, burnout, job satisfaction and general health of nurses', International Journal of Environmental Research and Public Health, 12(1), pp. 652-666. doi: 10.3390/ijerph120100652.

Khamisa, N., Peltzer, K. and Oldenburg, B. (2013) 'Burnout in relation to specific contributing factors and health outcomes among nurses: A systematic review', International Journal of Environmental Research and Public Health, 10(6), pp. 2214-2240. doi: 10.3390/ijerph10062214.

Kivimäki, M. et al. (2008) 'Job strain and ischaemic disease: does the inclusion of older employees in the cohort dilute the 
association? The WOLF Stockholm Study', Journal of Epidemiology and Community Health, 62(4), p. 372 LP$374 . \quad$ Available at: http://jech.bmj.com/content/62/4/372.ab stract.

Konstantinos, N. and Christina, O. (2008) 'Factors Influencing Stress and Job Satisfaction on Nurses Working in Psychiatric Unit: A Research Review', Heath Science Journal, 4, pp. 183-195.

Manwatkar, S. and Mathew, S. (2016) 'A Study To Assess The Effectiveness Of Self Instructional Module Among Staff Nurses Regarding Stress Management In Selected Hospitals Of The City', IOSR Journal of Nursing and Health Science, 5(4), pp. 01-03. doi: 10.9790/1959-0504050103.

Mark, G. and Smith, A. P. (2012) 'Occupational stress, job characteristics, coping, and the mental health of nurses', British Journal of Health Psychology. Blackwell Publishing Ltd, 17(3), pp. 505-521. doi: 10.1111/j.20448287.2011.02051.x.

Momeni, B. et al. (2016) 'The relationship between the quality of work life and sleep in nurses at the intensive care units of teaching hospitals in Mazandaran, Iran', mazujnms. Department of Medical-Surgical Nursing, Nasibeh Nursing \& Midwifery Faculty, Mazandaran University of Medical Sciences, Sari, Iran KW Intensive care unit (ICU) KW Nurse KW Quality of work life KW Sleep quality, 3(1), pp. 28-34. doi: 10.18869/acadpub.jnms.3.1.28.

Morsy, S. M. and Sabra, H. E. (2015) 'Relation Between Quality of Work Life and Nurses Job Satisfaction at Assiut University Hospitals', Al-Azhar Assiut Medical Journal, 13(1). Available at: http://www.aamj.eg.net/journals/pdf/234 6.pdf (Accessed: 18 November 2017).

Nishitani, N., Sakakibara, H. and Akiyama, I. (2013) 'Short Sleeping Time and Job Stress in Japanese White-Collar Workers', The Open Sleep Journal, 6(1), pp. 104-109. doi: 10.2174/1874620901306010104.

Nursalam (2012) Keperawatan Manajemen
Aplikasi Dalam Praktek Keperawatan Profesional. Jakarta: Salemba Medika.

Nursalam (2014) Metode Penelitian Ilmu Keperawatan: Pendekatan Praktis. 3rd edn. Jakarta: Salemba Medika.

de Paiva, L. C. et al. (2016) 'Risk factors identification for Burnout syndrome in nurses', International Archives of Medicine, pp. 1-7. doi: 10.3823/2199.

Papalia, D. E., Olds, S. W. and Feldman, R. D. (2007) Human Development. 10th edn. New York: McGraw Hill.

Qaisar, M. U., Rehman, M. S. and Suffyan, M. (2012) 'Exploring Effects of Organizational Commitment on Employee Performance: Implications for Human Resource Strategy', Interdisciplinary Journal of Contemporary Reserach in Business, 3(2000), pp. 248-255.

Sastroasmoro, S. and Ismael, S. (2011) Dasardasar Metodologi Penelitian Klinis. Jakarta: Binarupa Aksara.

Sharma, S. and Kamra, P. (2013) 'Patient Satisfaction with Nursing Care in Public and Private Hospitals', Nursing and Midwifery Research Journal, 9(3), p. 130.

Sirin, M. and Sokmen, S. M. (2015) 'Quality of Nursing Work Life Scale: The Psychometric Evaluation of the Turkish Version', International Journal of Caring Sciences, 8(3), pp. 543-554. Available at: www.internationaljournalofcaringscienc es.org (Accessed: 17 November 2017).

Suharti, N. and Daulima, N. (2013) Burnout dengan Kinerja Perawat di Rumah Sakit Metropolitan Medical Centre Jakarta. Universitas Indonesia.

Suresh, D. (2013) Quality of Nursing Work Life among nurses working in selected government and private hospitals in Thiruvananthapuram. Sree Chitra Tirunal Institute for Medical Sciences \& Technology. Available at: http://dspace.sctimst.ac.in/jspui/bitstrea $\mathrm{m} / 123456789 / 2265 / 1 / 6282$.pdf.

Thulth, A. S. and Sayej, S. (2015) 'Selected organizational factors affecting performance of professional nurses in North West Bank Governmental Hospitals', 6(7), pp. 100-110. 